\title{
KAJIAN MAKNA, NILAI DAN BENTUK LAGU TAWAR SEDENGE SEBAGAI LAGU SELINGAN DALAM UPACARA NASIONAL DI SMP NEGERI 1 TAKENGON KABUPATEN ACEH TENGAH
}

\author{
Amalia Putri Jayanti \\ Prodi Pendidikan Musik
}

\begin{abstract}
Amalia Putri Jayanti 2113340003. Assessment Form, Meaning, Value song Tawar Sedenge As song interlude in National Ceremony in junior high school 1 Central Aceh district. Essay. Sendratasik majors. Music Education Program. Faculty of Language and Art. Medan State University in 2015. This study discusses the meaning, value and form Tawar Sedenge song as the song interlude at a national ceremony. The research was conducted in order Gayo society, especially the younger generation can understand the meaning, value (meaning is the intention of the song lyric bargaining sedenge, while the value is to assess the meaning of a meaning) and the form of songs bargaining sedenge as anthem Gayo people who always sung on the great days, especially at the national ceremony in SMP Negeri 1 Takengon, Central Aceh district. The theory used in this research is the theory of meaning that examines denotative and connotative meaning, value theory, which examines the theory of form sentences, phrases and motifs, which are very useful in the study. The method used in this research is descriptive qualitative method. Research location in SMP Negeri 1 Takengon, Central Aceh district. The sample was a song that is sung sedenge bargaining as the song interlude in a national ceremony. The technique of collecting data through observation, interviews, documentation, and laboratory work. The data analysis technique used is descriptive qualitative analysis method that is accompanied by the presentation of data and drawing conclusions. According to the research done, it can be in the know that the meaning of the song bargaining sedenge based on the meaning of denotation and connotation contains a message to the community Gayo so grateful, and welfare of the land so that people Gayo Gayo rise and victorious from the downturn. The value contained in the song bargaining sedenge adalan value can increase the sense of nationalism is love of the homeland, which are vital values (education) and the spiritual (religious, beauty, culture) that have been arranged in a hierarchy. Tawar Sedenge song form that $A A B B A A B B$, consisting of 2 forms or themes that form a sentence and the sentence $B$.
\end{abstract}

Keywords: Study Meaning, Value, Forms, and Tawar Sedenge 
PENDAHULUAN

Negara Indonesia adalah negara yang sangat kaya akan suku (etnis) serta kesenian daerah. Dari sekian banyak kesenian daerah yang ada di Indonesia terdapat salah satu suku di Provinsi Nangroe Aceh Darusalam tepatnya di Kabupaten Aceh Tengah yaitu suku Gayo. Suku Gayo sangat kaya akan keberagaman jenis kesenian tradisionalnya seperti, Tari Munalo (penyambutan), Saman Gayo, Kekitiken (teka-teki), Kekeberen (prosalisan), Melengkan (pidato adat), Sebuku (puisi bertema sedih), dan Didong.

Salah satu tradisi lisan daerah Gayo Kabupaten Aceh Tengah adalah lagu Tawar Sedenge. Lagu Tawar Sedenge adalah lagu wajib bagi masyarakat Gayo Kabupaten Aceh Tengah, karena lagu Tawar Sedenge dinyanyikan pada saat perayaan hari-hari besar, dan upacara nasional yaitu upacara bendera setiap hari Senin di sekolah-sekolah, lagu Tawar Sedenge dinyanyikan pada saat setelah lagu Indonesia Raya dinyanyikan.
Lagu wajib Tawar Sedenge ini menggambarkan keadaan lingkungan tanah Gayo yang megah karena kaya akan sumber daya alamnya seperti kopi Gayo juga rempah-rempahnya, dan memberikan pesan kepada masyarakat Gayo agar terus bangkit dalam mengelola sumber daya alam yang melimpah, yang perlu adanya peran dari masyarakat Gayo untuk bersamasama maju agar tanah Gayo menajadi kota yang tetap terjaga kelestariannya serta masyarakatnya hidup sejahtera.

Lagu Tawar Sedenge yang diciptakan oleh seniman Gayo yaitu almarhum A.R Moese ini memiliki Syair lagu dalam bahasa Gayo yang mampu menggugah emosi setiap pendengar, sehingga pendengar mampu bereaksi atas pengertian syair lagu tersebut. Sebagai pendengar, manusia sering merasakan emosi dari suatu lagu. ini berarti manusia dapat merasakan, mengerti dan memahami maksud dan tujuan lagu tersebut. memahami isi dari suatu lagu berarti sudah dapat mengambil nilai dari lagu tersebut, yang akhirnya nilai 
membuat satu pemahaman baru akan sesuatu dan ini sangat mempengaruhi cara pandang dari seseorang sehingga dapat membuat semacam pergeseran pemikiran.

Pola pikir manusia dapat dikaitkan dengan pandangan hidup, yang membicarakan mengenai filosofi dari manusia itu sendiri atau sukunya sendiri. Pada dasarnya pandangan hidup ini sangat berpengaruh pada pola pikir, tindakan serta tujuan hidup. Pandangan hidup masyarakat Gayo bisa dilihat dari pepatah-pepatah atau sa'er yang ada di Gayo. Pepatahpepatah itulah yang dijadikan masyarakat Gayo sebagai pandangan hidup dalam melakukan suatu tindakkan, karena pepatah-pepatah tersebut memiliki makna penting pada masyarakat Gayo. Banyak sekali upaya masyarakat Gayo untuk melestarikan pepatah-pepatah tersebut, salah satu upaya itu adalah membuat lagu dengan menjadikan pepatah-pepatah tersebut sebagai lirik lagu, agar pepatah-pepatah tersebut tidak tenggelam dan tetap mamberikan pandangan hidup yang positif pada masyarakat Gayo.

Bentuk lagu Tawar Sedenge ini digarap dengan sederhana, sehingga dengan mudahnya dapat diingat oleh setiap masyarakat. Melodi-melodi yang khas dari lagu Tawar Sedenge ini sangat menarik perhatian dan dapat membuat setiap orang yang mendengarkan atau menyanyikan lagu Tawar Sedenge ini masuk kedalam suasana yang dimaksud oleh sang pencipta lagu yaitu almarhum A.R Moese.

Berdasarkan uraian diatas, penulis tertarik untuk melakukan penelitian dengan mengkaji makna, nilai dan bentuk lagu "Tawar Sedenge" dengan judul:"Kajian Makna, Nilai Dan Bentuk Lagu Tawar Sedenge Sebagai Lagu Selingan Dalam Upacara Nasional Di SMP Negeri 1 Kabupaten Aceh Tengah". Untuk dideskripsikan dalam bentuk karya ilmiah yang dikemas dalam bentuk skripsi. 
Menurut Piliang dalam bukunya Semiotika dan Hipersemiotika, (1981: 38):

Untuk meninjau makna yang terkandung dalam musik dan teks lagu tawar sedenge ini penulis menggunakan teori semiotika. Menurut Piliang (2010:19) menyatakan bahwa "Semiotika adalah ilmu tentang tanda dan kodekodenya serta penggunaannya dalam masyarakat."

Dengan menggunakan teori semiotika, seseorang boleh menganalisis makna dan pesan itu melibatkan semua bentuk perlakuan dan konteks kewujudannya baik dalam bentuk bahasa ataupun perbuatan, atau kedua-duanya sekaligus. Pengirim akan memilih tanda-tanda tertentu dan disusun secara sistematik untuk mewujudkan makna tertentu, pengirim bebas memilih tanda-tanda yang hendak digunakan maka makna bersifat subjektif. Oleh karena itu, hubungan antara tanda (lambang) dengan objek yang dilambangkan adalah berdasarkan imajinasi suatu objek.

Bahasa adalah sistem lambang (tanda) dimana lagu tawar sedenge yang didalam syair lagunya memakai bahasa Gayo, kebudayaan dilihat sebagai teks dalam lagu wajib rakyat Gayo yang mana masyarakat mempunyai peran sebagai pengamat tanda-tanda (interpretan) dalam usaha kita untuk mengetahui makna lagu tawar sedenge (objek) tersebut.

Makna adalah suatu yang tersirat dibalik bentuk dan aspek isi suatu kata atau teks yang didalamnya berdasarkan latar belakang tanda, sosial, budayanya masing-masing dan kemudian terbagi menjadi dua bagian yaitu makna konotatif dan makna denotatif. Makna konotatif adalah makna kata yang mengandung arti tambahan (kiasan) atau tidak langsung, sedangkan makna denotatif adalah kata yang tidak mengandung arti tambahan, atau langsung yang disebut makna sebenarnya. Sesuai dengan topik penelitian ini yaitu mengenai lagu tawar sedenge menggunakan bahasa Gayo yang tidak dimengerti atau bisa berbeda arti jika hanya mengartikan kata demi kata yang terdapat dalam teks nyanyian tersebut sehingga diperlukan teori semiotika ini untuk 
mengetahui makna seutuhnya pada masyarakat Gayo.

\section{Menurut Suratman dkk} dalam bukunya Ilmu Sosia Budaya Dasar, (2013: 186) :

Nilai adalah sesuatu yang berhubungan dengan manusia, baik dalam bidang etika yang mengatur kehidupan manusia dalam kehidupan sehari-hari maupun bidang estetika yang berhubungan dengan persoalan keindahan, bahkan nilai masuk etika manusia memahami agama dan keyakinan beragama. Sesuat dipandang bernilai karena sesuatu itu berguna, maka disebut nilai kegunaan, bila benar dipandang bernilai maka disebut nilai kebenaran, indah dipandang bernilai maka disebut nilai keindahan (estetis), baik dipandang bernilai maka disebut nilai moral (etis), religius dipandang bernilai maka disebut nilai keagamaan. Oleh karena itu, nilai memiliki polaritas dan hireaki.

Menurut Budilinggono dalam bukunya Bentuk dan Analisis Musik (1993 : 19):
"Bentuk lagu adalah suatu skema atau susunan yang utuh dari beberapa frase. Frase-frase tersebut harus dibatasi dengan kadens yang jelas. Sebuah frase kurang lebih terdiri atas 4 birama. Dari sebuah frase tersebut dapat dibentuk menjadi sebuah kalimat yang umumnya terdiri atas 8 birama. Frase pertama disebut frase pertanyaan, sedangkan frase kedua disebut frase jawaban."

Maka dari itu untuk mengetahui bentuk lagu tawar sedenge harus dilakukan peenganalisisan susunan utuh dari beberapa frase yaitu frase pertanyaan dan frase jawaban yang dapat di analisis dalam berbagai bentuk lagu satu, bentuk lagu dua maupun bentuk lagu tiga. Secara simbol dapat di jelaskan sebagai berikut: A-A',A-B,A-B-A,A-B-C,AB-A-C, dan sebagainya.

\section{Lokasi dan Waktu Penelitian}

Lokasi penelitian yang dipilih untuk mengadakan penelitian ini yaitu di SMP Negeri 1 Takengon kabupaten Aceh tengah. 


\section{Populasi dan Sampel}

Populasi

Menurut Sugiyono (2010:80)

Populasi adalah generalisasi yang terdiri atas objek atau subjek yang mempunyai kualitas dan karakteristik tertentu yang ditetapkan penulis untuk dipelajari dan kemudian ditarik kesimpulannya. Untuk menentukan populasi berdasarkan pendapat diatas, maka populasi dalam penelitian ini adalah rekaman lagu Tawar Sedenge, seniman-seniman Gayo, dan seluruh Guru dan siswa/siswi SMP Negeri 1 Takengon yang mengikuti upacara nasional di Gayo Kabupaten Aceh Tengah.

\section{Sampel}

Sample dalam penelitian ini adalah lagu rekaman selingan Tawar Sedenge, salah satu seniman Gayo, guru kesenian dan guru PKn, serta siswa-siswi anggota paduan suara yang menyanyikan lagu Tawar Sedenge pada upacara nasional di SMP Negeri 1 Takengon Kabupaten Aceh Tengah

\section{Teknik Pengumpulan Data}

Teknik pengumpulan data yang dilakukan adalah sebagai berikut:

1. Observasi

2. Wawancara

3. Dokumentasi

4. Studi Pustaka

5. Kerja Laboratorium

\section{Teknik Analisis Data}

Teknik analisis data yang digunakan adalah deskripsi yaitu sebagai prosedur pemecahan masalah yang diselidiki dengan menggambarkan keadaan objek penelitian pada saat sekarang, data dan fakta yang terkumpul harus diolah dan ditafsirkan.

\section{ISI}

Asal Usul Sendratari Peteri Bensu Pada Masyarakat Gayo

Berdasarkan informasi yang di peroleh dari wawancara bersama Nasrah (18 Agustus 2015), Lagu Tawar Sedenge diciptakan seniman Gayo yaitu Almarhum Ar Moese pada tahun 1957. Tawar sedenge secara harafiah mempunyai arti Tawar "penyejuk" Sedenge "dunia" yang berarti "penyejuk Dunia”. Lagu 
Tawar Sedenge digunakan oleh masyarakat Gayo Kabupaten Aceh Tengah sebagai bentuk komunikasi untuk menyampaikan pesan, tujuan dan maksud.

\section{Terciptanya lagu Tawar} Sedenge, di inspirasikan berdasarkan keadaan lingkungan masyarakat Gayo pada saat itu yang masih belum berkembang dan banyak campur tangan dari orang-orang pendatang yang menguasai tanah Gayo khususnya sumber daya alamnya.

\section{Lagu wajib Tawar Sedenge}

ini menggambarkan keadaan lingkungan tanah Gayo yang megah karna kaya akan sumber daya alamnya seperti kopi Gayo juga rempah-rempahnya, dan memberikan pesan kepada masyarakat Gayo agar terus bangkit dalam mengelola sumber daya alam yang melimpah, yang perlu adanya peran dari masyarakat Gayo khususnya genenrasi muda untuk bersama-sama maju agar tanah Gayo menajadi kota yang tetap terjaga kelestariannya serta masyarakatnya hidup sejahtera.
Pada awalnya lagu tawar sedenge hanya dinyanyikan pada acara - acara seni yang ada di Gayo. Namun dengan adanya kesadaran masyarakat Gayo khususnya pihak pihak sekolah akan makna dan nilai syair lagu tawar sedenge yang dapat meningkatkan nasionalisme siswa akan tanah Gayo, sehingga lagu tawar sedenge menjadi lagu wajib bagi masyarakat Gayo dan kerap dinyanyikan sebagai lagu selingan dalam upacara nasional di Takengon Kabupaten Aceh Tengah. Sebab dari itu lagu tawar sedenge memiliki peran penting bagi generasi muda, karena lagu tawar sedenge memiliki nilai dan makna yang sangat berguna untuk membangun rasa cinta mereka terhadap tanah air.

\section{Makna Lagu Tawar Sedenge}

Lagu Tawar sedenge ini, memiliki makna-makna semiosis yang hanya bisa di dekati dengan cara menyelami cara berpikir masyarakat yang menyanyikan lagu ini.

Semua bentuk kalimat dalam syair lagu tawar sedenge tersebut 
terbagi dalam 2 bentuk kalimat yaitu kalimat yang mudah dimengerti dan dipahami artinya sehingga dengan mudahnya mengambil makna dari kalimat tersebut, karena menggunakan arti sebenarnya (denotatif) yang mana hanya terdapat bait syair pertama dan keempat lagu tawar sedenge. Sedangkan kalimat selebihnya menggunakan pepatahpepatah Gayo sebagai liriknya yang susah dimengerti atau bisa berbeda arti jika hanya mengartikan kata demi kata (konotatif) seperti yang banyak terdapat pada bait ke 2, 3, 5, 6, 7 dan bait terakhir.

\section{Nilai-Nilai Lagu Tawar Sedenge}

berdasarkan pengertian dan fungsinya, lagu tawar sedenge memiliki nilai bagi masyarakat yang menyanyikan dan mendengarkan lagu tawar sedenge tersebut. Sesuai dengan teori yang digunakan penulis, nilai yang terdapat dalam syair lagu tawar sedenge akan diteliti berdasarkan hierarki atau sebuah urutan tingkatan yang terbagi atas nilai material, nilai vital dan nilai kerohanian. Tetapi pada penelitian yang penulis lakukan, ternyata penulis menemukan penambahan nilai pada syair lagu tawar sedenge yaitu nilai keindahan.

Syair lagu tawar sedenge banyak mengandung nilai, yaitu nilai vital (pendidikan) serta nilai kerohanian (religi, keindahan, dan kebudayaan), yang telah disususn secara hirarki yaitu pada tingkat pertama nilai kerohanian dan tingkat kedua nilai vital. Untuk memudahkan penulis meneliti susunan hierarki dalam lagu tawar sedenge, maka penulis menggabungkan nilai kebudayaan ke dalam unsur nilai kerohanian karena Murdowo dalam Suratman dkk (2013 : 32) mengatakan " Kultur itu termasuk dalam nilai kerohanian".

\section{Bentuk Lagu Tawar Sedenge}

Notasi asli pada lagu tawar sedenge menggunakan notasi angka, tetapi pada penelitian ini penulis menggunakan notasi balok agar dapat memudahkan penulis untuk menganalisisnya. Lagu tawar sedenge ini pada dasarnya dibuat dengan nada dasar $\mathrm{D}=$ do dengan birama $3 / 4$, sama halnya dengan lagu 
tawar sedenge yang biasa dinyanyikan siswa-siswi SMP Negeri 1 Takengon.

Bentuk lagu tawar sedenge berdasarkan rangkanya terdiri dari A-A-B-B-A-A-B-B, yang terdabat dua bagian kalimat yaitu kalimat A dan kalimat B, pada kalimat A terdapat dua frase yaitu frase pertanyaan (a) dan frase jawaban (x), pada kalimat B terdapat 2 frase yaitu frase pertanyaan (b) dan frase jawaban (y) selanjutnya motif yang terdapat pada bentuk lagu tawar sedenge pada kalimat A motif 1 (m1), motif 1 (pembalikan) $\mathrm{m} 1$ ' (sekuens turun dan pengembangan motif elongated. Pada kalimat B motif 2 (m2), m2 (pembalikan), m2' (sekuens turun) dan pengembangan motif elongated..

\section{KESIMPULAN}

Dari hasil penelitian yang dilakukan di lapangan dan penjelasan yang sudah di uraikan mulai dari latar belakang hingga pembahasan, maka dapat di tarik beberapa kesimpulan sebagai berikut:
1. Makna lagu Tawar sedenge yang disajikan berisi pesan kepada masyarakat Gayo terkhususnya para generasi muda, agar selalu memperjuang kan dan membangkitkan tanah Gayo dengan memelihara serta melestarikan harta peninggalan nenek moyang, yaitu sumber daya alamnya agar tidak dikuasai oleh bangsa lain (para penjajah).

2. Syair yang terdapat dalam lagu Tawar sedenge memiliki nilai yang berhubungan dengan nilai vital dan kerohanian, yang berperan dalam meningkatkan rasa cinta siswa-siswi SMP Negeri 1 Takengon terhadap tanah air, melalui syair lagu tawar sedenge yang menjadi sarana untuk meningkatkan nasionalisme siswa. Syair lagu Tawar sedenge berfungsi sebagai alat informasi kepada siswa didalamnya menjelaskan bagaimana bahwa generasi muda lah yang akan memimpin $d_{i} 74$ 


$$
\begin{aligned}
& \text { mensejahterakan dan } \\
& \text { melindungi tanah Gayo dari } \\
& \text { bangsa lain (penjajah). } \\
& \text { Disinilah peran lagu Tawar } \\
& \text { sedenge yang memberikan } \\
& \text { informasi serta melahirkan } \\
& \text { sikap atas cinta terhadap } \\
& \text { tanah air dengan } \\
& \text { menumbuhkan rasa } \\
& \text { nasionalisme siswa serta } \\
& \text { siswa mengetahui bahwa } \\
& \text { tanah air mereka sangat } \\
& \text { membutuhkan mereka dalam } \\
& \text { membangkitkan dan } \\
& \text { melestarikan tanah Gayo. }
\end{aligned}
$$

3. Bentuk lagu Tawar sedenge di garap dengan sederhana, sehingga dengan mudahnya dapat diingat oleh setiap masyarakat, bentuk lagu tawar sedenge terdiri dari 2 bentuk yaiyu bentuk A dan bentuk $\mathrm{B}$ dengan struktur AABBAABB.

\section{Saran}

Berdasarkan kesimpulan di atas, maka dapat diambil beberapa saran sebagai berikut :

1. Bagi Dinas Pendidikan lagu Tawar sedenge diadakan sebagai perlombaan paduan suara tingkat pelajar, agar generasi muda masyarakat Gayo dapat lebih mengenal lagu tawar sedenge, dalam perlombaan yang berhubungan dengan, kesenian, sejarah serta kebudayaan Gayo sehingga generasi muda dapat dengan mudah mengerti dan mengetahui keadaan daerahnya, mengetahui jelas kebudayaannya, dan semakin menumbuhkan rasa cintanya terhadap tanah Gayo.

2. Bagi Guru agar lebih kreatif lagi dalam memilih lagu-lagu daerah lainnya untuk dinyanyikan dan dipelajari, yang memiliki manfaat bagi para generasi muda.

\section{DAFTAR PUSTAKA}

\section{Al. Sukohardi. 2012. Teori Musik Umum. Yogyakarta}

Banoe, Panoe. 2007. Kamus Musik. Yogyakarta. Kanisius.

Budilinggono. 1993. Bentuk dan Analisis Musik. Jakarta. Depdikbud. 
Bungin, Burhan. 2007. Metode Penelitian Kualitatif. Jakarta. Rajagrafindo.

Hadeli. 2006. Metode penelitian pendidikan. Padang. Quantum Teaching.

Hardjana, Suka. 2004. Musik antara kritik dan apresiasi. Jakarta. Buku Kompas.

Hasibuan, Melayu. 2006.Manajemen Sumber Daya Manusia. Jakarta. Bumi Aksara.

Ibrahim, Mahmud, 2005. Syari'at dan Adat Istiadat. Takengon: Yayasan Mahmuda. Maqamam

Maryeni. 2005. Metode Penulisan Kebudayaan. Jakarta. Bumi Aksara.

Netriosa, Arifni. 2003. Simbol Dalam Seni Merupakan Simbol Presentasional. Artikel USU.
Piliang, Yasraf Amir. 2010. Semiotika dan Hipersemiotika. Kode, Gaya, dan Matinya Makna. Bandung. Matahari.

Suratman dkk. 2013. Ilmu Sosial Budaya Dasar. Malang. Intimedia.

Suryanita , Wahyuni. 2012. Laboratorium sebagai Pusat Sumber Belajar.

Sugiyono. 2008. Metode Penelitian Kuantitatif, Kualitatif dan $R \& D$. Bandung. Alfabeta.

Sugiyono. 2010. Metode Penelitian Kuantitatif kualitatif dan $R \& D$. Bandung. Alfabeta. 